\title{
The Effect of Environmental Temperature on Airway Resistance in the Asthmatic Ghild
}

\author{
Frank Rodriguez-Martinez, Armand V. Mascia, and Robert B. Mellins ${ }^{[2]}$ \\ Pulmonary Division, Department of Pediatrics, Columbia University, College of Physicians and Surgeons and Babies Hospital, New York, \\ and the Blythedale Children's Hospital, Valhalla, New York, USA
}

\section{Extract}

To test the hypothesis that receptors to cold are in the upper air passages, the effect of a change in environmental temperature from a high of $90-95^{\circ} \mathrm{F}$ to a low of $50-55^{\circ} \mathrm{F}$ was studied in a group of eight children with a history of chronic asthma before and after applying topical anesthesia to nose and pharynx; nine children without cardiac or pulmonary disease served as control subjects. The forced expiratory volume in $1 \mathrm{sec}$ $\left(\mathrm{FEV}_{1}\right)$, the maximum voluntary ventilation (MVV), and the maximum expiratory flow rates at $50 \%\left(\dot{\mathrm{V}}_{50}\right)$ and $25 \%\left(\dot{\mathrm{V}}_{25}\right)$ of the vital capacity were used to assess airflow resistance. In the untreated asthmatic there was a significant fall in all test values at the low temperature $(P<0.01)$, which indicated an increase in airflow resistance. When nose and pharynx of the asthmatic patients were sprayed with lidocaine before decrease of the environmental temperature, there was no significant difference in test results $(P>0.05)$. These results offer additional evidence in support of the reflex nature of cold-induced bronchoconstriction with cold-sensitive receptors present in the upper airways.

\section{Speculation}

The increase in airway resistance noted in the asthmatic patients as environmental temperature was reduced, even though the absolute level was not very low, indicates that there are temperature-sensitive receptors in the upper airways which respond to a change in temperature as well as to the absolute level of temperature.

\section{Introduction}

A variety of experimental studies, mostly in adult subjects $[5,6,9,14-16]$, have corroborated the general clinical impression that inhalation of cold air can produce an increase in airflow resistance in some individuals, especially in those with chronic lung disease. The increase in airflow resistance seems to result mainly from reflex bronchoconstriction initiated by stimulation of receptors in the airways and not from the effects of surface cooling $[14,16]$. Because even extremely cold ambient air is warmed close to body temperature before it reaches the carina $[1,2,7,10]$, it seems likely that the receptors of the reflex response to cold inhalation are in the upper respiratory tract. To test the hypothesis we studied the effect of cold air inhalation on airway resistance in a group of children with histories of severe and chronic asthma before and after applying topical anethesia to the nose and pharynx.

\section{Materials and Methods}

Eight children, four boys and four girls, aged 11-16 years, who had received at least 1 year of residential 
Table I. Physical characteristics and physiologic data ${ }^{1}$

\begin{tabular}{|c|c|c|}
\hline & Normal subjects & Asthmatic patients \\
\hline Number & 9 & 8 \\
\hline \multicolumn{3}{|c|}{ Age, years } \\
\hline Mean & 14 & 14 \\
\hline Range & $11-18$ & $11-16$ \\
\hline \multicolumn{3}{|l|}{ Sex } \\
\hline Male & 4 & 4 \\
\hline Female & 5 & 4 \\
\hline \multicolumn{3}{|c|}{ Height, cm } \\
\hline Mean & 160 & 157 \\
\hline SEM & 5.1 & 3.6 \\
\hline \multicolumn{3}{|c|}{$\mathrm{FEV}_{1} / \mathrm{VC} \%$} \\
\hline Mean & 92 & $74^{2}$ \\
\hline SEM & 1.4 & 3.0 \\
\hline \multicolumn{3}{|l|}{ MVV } \\
\hline Mean & 78 & 56 \\
\hline SEM & 8.7 & 7.9 \\
\hline \multicolumn{3}{|l|}{$\dot{\mathrm{V}}_{50}$} \\
\hline Mean & 2.83 & $1.33^{2}$ \\
\hline SEM & 0.36 & 0.14 \\
\hline \multicolumn{3}{|l|}{$\dot{\mathrm{V}}_{25}$} \\
\hline Mean & 2.47 & $0.65^{2}$ \\
\hline SEM & 0.44 & 0.08 \\
\hline
\end{tabular}

$1 \mathrm{FEV}_{1} / \mathrm{VC}^{2} \%$ : The forced expiratory volume at $1 \mathrm{sec}$ expressed as a percentage of the vital capacity; $\mathrm{MVV}$ : maximum voluntary ventilation; $\dot{\mathrm{V}}_{50}$ : maximum expiratory flow rate at $50 \%$ of the vital capacity; $\dot{\mathrm{V}}_{25}$ : maximum expiratory flow rate at $25 \%$ of the vital capacity.

${ }^{2} P<0.01$ in comparison with the normal.

treatment at the Blythedale Children's Hospital because of severe chronic asthma, were studied (Table I). All had strong family histories of allergy and had associated allergic rhinitis or atopic dermatitis. The duration of asthma varied from 5 to 14 years. During the period of residential treatment, the severity and frequency of acute exacerbations of asthma had diminished and wheezing was no longer continuous. Although all had received corticosteroids in the past, none had received any for a period of at least 6 months before the study. They were free of any signs of upper respiratory infection, cough, or wheezing, and received no medication on the day of study.

Nine children, five girls and four boys, aged 11-18 years, with no historic or clinical evidence of pulmonary or heart disease served as normal control subjects (Table I). These children were at Blythedale Children's Hospital for a variety of orthopedic conditions which required long term residential treatment.

All studies were performed in a special unit which permitted temperature and humidity to be controlled independently. Temperature could be maintained between $50^{\circ}$ and $100^{\circ} \mathrm{F}$ with a tolerance of $2^{\circ} \mathrm{F}$ and the relative humidity between 20 and $60 \%$ with a tolerance of $5 \%$. An efficient filtering and air exchanging system maintained the unit free of dusts and inhalants.

The $\mathrm{FEV}_{1}$ expressed as a percentage of the vital capacity (VC \%), the MVV, and the $\dot{\mathrm{V}}_{25}$ were $\dot{\mathrm{V}}_{\tilde{5} 0}$ and used to assess airflow resistance.

The $\mathrm{FEV}_{1}$ expressed as a percentage of the vital capacity (VC \%), the MVV, and the $\dot{\mathrm{V}}_{50}$ and $\dot{\mathrm{V}}_{25}$ were determined from flow volume curves obtained using a simple flow volume device [13]. All tests were done in triplicate and the highest value was used for the analysis of the data.

The volumes of the spirometer and flow volume device were corrected to body temperature and pressure saturated by factors obtained from separate studies using thermocouples to measure the instantaneous changes in instrument temperature when the expired volumes and ambient temperatures were in the same range as those used in the present study.

The children, all of whom had been previously trained to use the equipment, were admitted to the unit in pairs. Appropriate dress was used to keep them comfortable as temperature in the unit was varied. The children were allowed to breathe through the nose or mouth except during the performance of the test maneuvers during which a noseclip was applied.

To test the effect of variations in temperatures on airflow resistance, the studies were performed at a high ambient temperature of $90-95^{\circ} \mathrm{F}$ and at a low ambient temperature of $50-55^{\circ} \mathrm{F}$. The tests were performed after the patient had been in the room for $1 \mathrm{hr}$ after any change in temperature. The same tests were repeated at the high and low temperature in a separate series of experiments in the asthmatic group after spraying $4 \%$ lidocaine to the nose and pharynx. For this purpose a hand atomizer was used and a maximum close of $0.2 \mathrm{cc}(8 \mathrm{mg})$ was administered. To minimize deposition down into the respiratory tract, spraying was performed during breath holding after inspiration. In order to exclude psychologic factors, the tests were also repeated after nasopharyngeal spray with isotonic saline.

The relative humidity at both the high and low temperature varied from 30-60\%. However, for any given patient, the relative humidity was kept constant at the high and low temperatures, except during the early studies when it varied by as much as $30 \%$. To test whether this could produce any significant change in our results, a separate study was performed in five asthmatic patients and five normal subjects in which the relative humidity was varied from a high of 
$55-65 \%$ to a low of $25-35 \%$. In these experiments the temperature was kept constant at $70^{\circ} \mathrm{F}$.

On the average, all tests were repeated at the high and low ambient temperature and humidity on 5 separate days, and the order was varied in different study periods except in the lidlocaine studies. In the latter, the tests were always done at the high temperature before and after application of lidocaine and then at the low temperature.

For statistical evaluation of the data, the mean clifference between the high and low levels of temperatures or relative humidity was determined for each individual and then for each group. Paired analysis was used throughout.

\section{Results}

The physiologic data shown in Table I were obtained at normal ambient temperatures during an asymptomatic interval several weeks before the studies of envi-

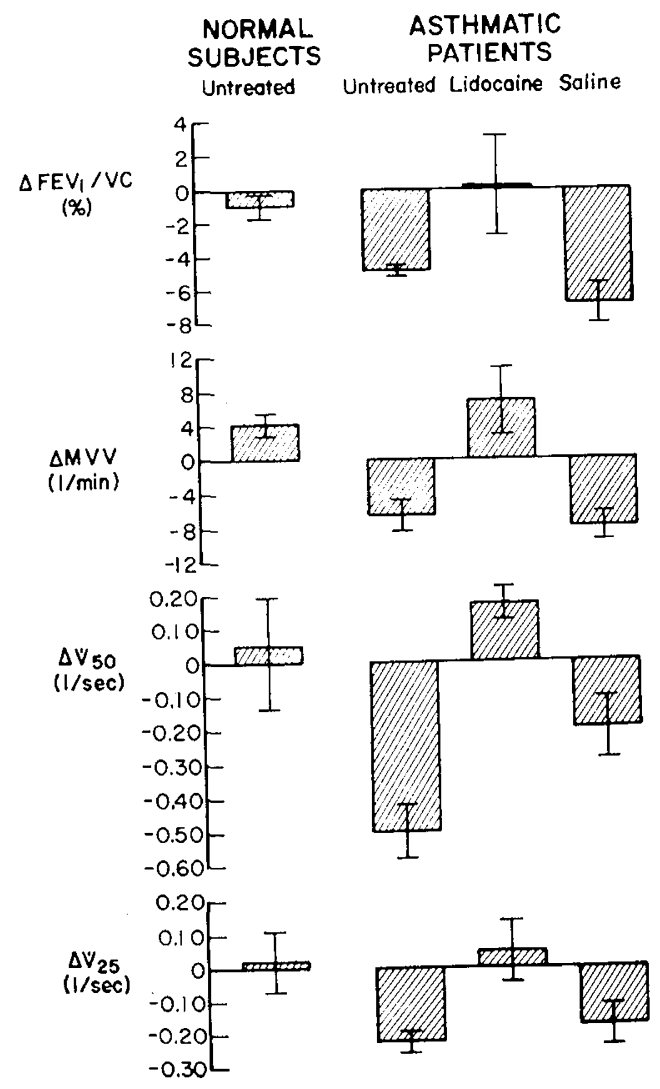

Fig. 1. The effect on lung function of a change in ambient temperature from a high of $90-95^{\circ} \mathrm{F}$ to a low of $50-55^{\circ} \mathrm{F}$ in nine normal subjects and eight asthmatic patients. The latter were also tested after the nasopharynx was sprayed with lidocaine and isotonic saline. See Table I for explanation of symbols. ronmental temperature. Although the two groups were comparable with respect to age, size, and sex distribution, all of the values for tests of airway resistance except the MVV were significantly lower $(P<0.01)$ in the asthmatic patients.

The mean clifference betwen the values obtained at the high and the low temperatures is shown in Fig. 1. In normal subjects there was no significant difference $(P>0.05)$. By contrast, in the untreated asthmatic patients, there was a significant fall in all test values at the low temperature $(P<0.01)$, which indicated an increase in airflow resistance. When nose and the pharynx of the asthmatic patients were sprayed with lidocaine before decrease of the environmental temperature, there was no significant difference in test results $(P>0.05)$. When nose and pharynx were sprayed with isotonic saline, however, a significant fall in test results $(P<0.01)$ was again seen at the low environmental temperature.

Figure 2 shows the effect on lung function of a change in relative humidity from a high of $55-65 \%$ to a low of $25-35 \%$. None of the changes shown in either the asthmatic or the normal subjects is significant $\langle P\rangle$ $0.05)$.

\section{Discussion}

The results of the present study demonstrate that a decrease in ambient temperatures causes an increase in airway resistance in children with chronic asthma. It has been suggested that this cold-induced increase in airflow resistances is caused mainly by reflex bronchoconstriction from stimulation of irritant receptors in the airway mucosa [14]. The efferent pathway of this reflex mechanism appears to be mediated via the vagus nerve, inasmuch as it has been shown to be abolished by atropine in man [14] and by sectioning or cooling of the vagus or by atropine in animals [11, 12]. Although the effect of atropine on cold-induced bronchoconstriction was not studied systematically in the present work, we did note that atropine prevented an increase in airway resistance in the three patients to whom it was given.

Additional evidence in support of the reflex nature of cold-induced bronchoconstriction is provided by the present observation that application of topical anesthesia to nose and pharynx of the asthmatic group prevented the increase in airway resistance induced by inhalation of cold air.

Although reflex bronchoconstriction has been demonstrated from receptors in the larynx and lower res- 


\section{NORMAL ASTHMATIC SUBJECTS PATIENTS}

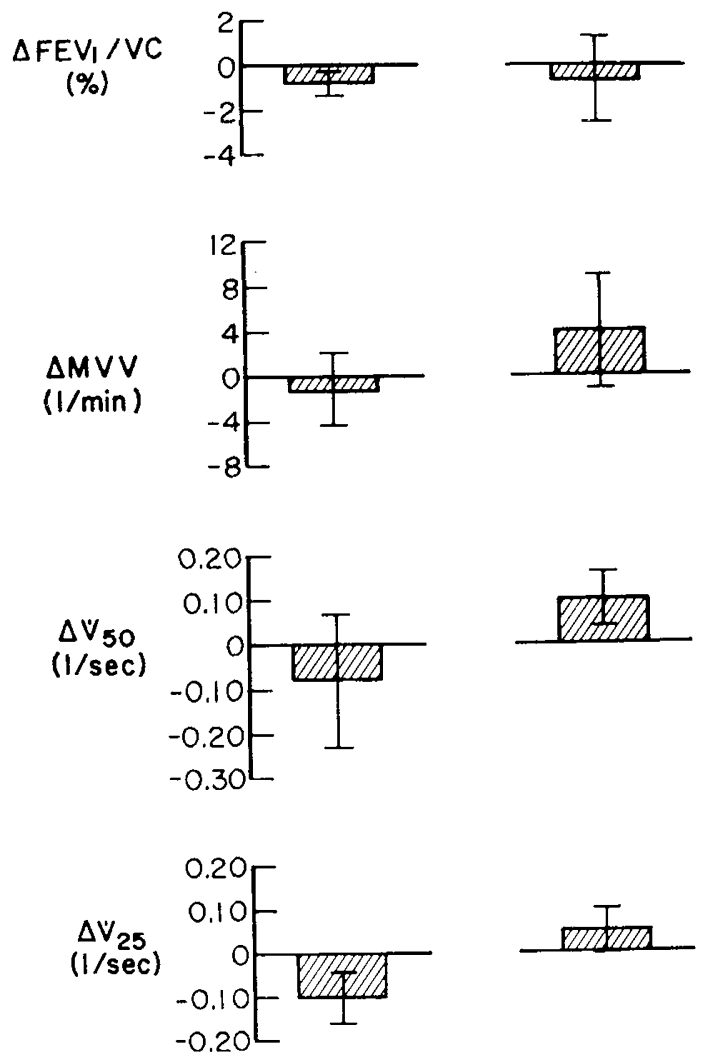

Fig. 2. The effect on lung function of a change in relative humidity from a high of $55-65 \%$ to a low of $25-35 \%$ in five normal subjects and five asthmatic patients. See Table I for explanation of symbols.

piratory tract, there is conflicting evidence with regard to the presence of such receptors in the upper respiratory tract $[8,11,17]$. The present study provides evidence for the existence of supralaryngeal receptors capable of initiating reflex bronchoconstriction in response to cold inhalation. The precise localization of these receptors within the upper air passages is limited for at least two reasons. (l) Although the nose and throat were exposed to ambient temperatures for the entire hour preceding the tests, only the upper airways proximal to the nose were exposed during the actual performance of the test maneuvers because of the need to use a mouth piece and nose clip. (2) Although the method of application of lidocaine was designed to confine the drug to the nasopharynx, we cannot exclude the presence of cold-sensitive receptors just proximal to this area, because it is possible that some spray settled on the epiglottis.
The small dose of lidocaine used as a local anesthetic, on the average $0.15 \mathrm{mg} / \mathrm{kg}$, makes it highly unlikely that the results of the present study could be attributed to a systemic effect following absorption from mucosal surfaces. The observation of an increase in airflow resistance after cold inhalation in the asthmatic group after substitution of normal saline for lidocaine makes it unlikely that psychologic factors were responsible for the results with lidocaine.

The hyperresponsiveness of asthmatic patients to a variety of stimuli is well known $[3,14]$. The detection of cold-induced bronchoconstriction in asthmatic but not in normal children indicates that the temperaturesensitive receptors are also sensitized in asthma. The absolute levels of temperature were not very low in the present study, which indicates that the temperaturesensitive receptors respond to a change in temperature as well as the absolute level.

Although the variations in humidity in the present study were limited to the range between 25 and $65 \%$, the results corroborated previous findings [4] that humidity plays no role in the bronchoconstriction produced by cold air inhalation.

\section{Summary}

The effect of a change in environmental temperature from a high of $90-95^{\circ}$ to a low of $50-55^{\circ} \mathrm{F}$ on the airway resistance of eight children with histories of severe and chronic asthma, and nine control children was studied in a specially designed chamber. A significant increase in airway resistance was noticed in the asthmatic group but not in the control group at the low environmental temperature. This increase in airway resistance could be blocked by topical anesthesia of the nose and pharynx. Variations in relative humidity produced no effect on airway resistance. The results are consistent with the hypothesis that inhalation of cold air stimulates upper airway receptors, which produces reflex bronchoconstriction.

\section{References and Notes}

1. Cole, P.: Further observations on conditioning of respiratory air. J. Laryngol. Otol., 67: 669 (1953).

2. Cole, P.: Recordings of respiratory air temperature. J. Laryngol. Otol., 68: 295 (1954).

3. Curry, J. J.: The action of histamine on the respiratory tract in normal and asthmatic subjects. J. Clin. Invest., 25: 785 (1946).

4. Fontana, V. J., Fost, A., and Rappaport, I.: Effects of rapid change in humidity in pulmonary function studies in normal 
and asthmatic children in a controlled environment. J. Allergy, 43: 16 (1969).

5. Guleria, J. S., Talmar, J. R., Malhotra, O. P., and Pande, J. N.: Effect of breathing cold air on pulmonary mechanics in normal man. J. Appl. Physiol., 27: 320 (1969).

6. Hsieh, Y. G., Frayser, R., and Ross, J. C.: The effect of cold air inhalation on ventilation in normal subjects and in patients with chronic obstructive pulmonary diseases. Amer. Rev. Resp. Dis., 98: 613 (1968).

7. INGelstedt, S.: Studics on the conditioning of air in the respiratory tract. Acta Oto-laryngol. Suppl., 1: 131 (1956).

8. Kaufman, J., AND Wright, G. W.: The effect of nasal and nasopharynegal irritation on airway resistance in man. Amer. Rev. Resp. Dis., 100: 626 (1969).

9. Millar, J. S., Nairn, J. R., Unkles, R. D., and MCNeill, R. S.: Cold air and ventilatory function. Brit. J. Dis. Chest, 59: 23 (1965).

10. Moritz, A. R., AND Weisigrr, J. R.: Effects of cold air on the air passages and lungs: Experimental investigations. Arch. Int. Med., 75: 233 (1945).

I1. Nadel, J. A., And Wrddicombe, J. G.: Reflex effects of upper airway irritation on total lung resistance and blood pressure. J. Appl. Physiol., 17: 861 (1962).

12. NADEL, J. A.: Structure-function relationship in the airways: Bronchoconstriction mediated via vagus nerves or bronchial arteries; peripheral lung constriction mediated via pulmonary arteries. Med. Thorac., 22: 231 (1965).

13. Peters, J. M., Mead, J., AND Van Ganse, W. F.: A simple flow- volume device for measuring ventilatory function in the field. Amer. Rev. Resp. Dis., 99: 617 (1969).

14. Simonsson, B. G., Jacois, F. M., and Nadel, J. A.: Role of autonomic nervous system and the cough reflex in the increased responsiveness of airways in patients with obstructive airway disease. J. Clin. Invest., 46: 1812 (1967).

15. Spicer, W. S., Jr., Reinke, W. A., and Herr, H. D.: Effects of environment upon respiratory function. II. Daily studies in patients with chronic obstructive lung disease. Arch. Environ. Health, 13: 53 (1966).

16. Wells, R. E., JR., Walker, J. E. C., and Hickler, R. E.: Effects of cold air on respiratory airflow resistance in patients with respiratory-tract diseasc. New Engl. J. Med., 263: 268 (1960).

17. Widdicombe, J. G.: Regulation of trachcobronchial smooth muscle. Physiol. Rev., 43: 1 (1963).

18. Pulmonar, Jones Medical Instrument Company, Chicago, Ill.

19. We are grateful to Miss Eva Piedmonti for her tcchnical assistance.

20. Dr. F. Rodriquez-Martinez is a Fellow of the National Tuberculosis and Respiratory Disease Association.

21. This work was supported in part by a grant from the Henry Kaufmann Foundation.

22. Requests for reprints should be addressed to: Robert B. MeLI.INS, M.D., Columbia-Presbyterian Medical Center, 622 West 168 St., New York, N.Y. 10032 (USA).

23. Accepted for publication February 28, 1973. 